\title{
Rheumatic Fever (RF) and Rheumatic Heart Disease (RHD) Prevention and COntrol Program in Nepal.
}

\section{Regmi $\mathrm{PR}^{\star}$, Upadhyaya $\mathrm{AB}^{\star}$}

*Program director, National RF/RHD prevention and control program, Nepal Heart Foundation/MOH \& $\mathrm{P}$

*President, Nepal Heart Foundation

\section{INTRODUCTION}

Ministry of Health and population, Government of Nepal announced the launch of National program for prevention and control of RF/RHD in Nepal in Ashad 2063 BS. Implementation of this program started on 15 Ashad 2064 with technical and organization support from Nepal Heart Foundation. Budget allocated for this Program in fiscal year 2063/064 was Nrs. 30 Lakhs, in 2064/065 Nrs. 40 Lakhs and in 2065/66 Nrs 10 Lakhs. This is the first program in Nepal launched by the government for prevention \& control of heart disease. Nepal Heart foundation is the main authorized organization for implementation of this program.

\section{Background:}

$\mathrm{RF}$ is an inflammatory syndrome related to beta-heamolytic group A streptococcal infection, mainly of the throat. Characteristically it tends to recur. The name rheumatic fever emphasizes involvement of the joints, but it is the involvement of the heart that makes it important. The attack of RF may affect the heart, causing damages to the heart valves and leading to high morbidity and mortality. RF and RHD are common in Nepal as well as other developing countries. Prevalence of RHD among school children in Kathmandu was reported to be 1.35 per 1000 in 1991, 1.2 per 1000 in 1997 and 2003 (13). This shows the prevalence of RHD remains of same during the last decade in Kathmandu city. There are no national data on RHD prevalence reflecting the situation in whole country. Nepal heart foundation estimates the prevalence of RHD in Nepal to be 2 per 1000 in school children. In Nepalese population of 27 million the incidence of RF is estimated to be 15000 per year and the incidence of RHD 7500 per year.

RF and RHD are preventable diseases. In Nepal the cost of Secondary prevention for an affected child is approximately 6 USD per year, but the Surgical treatment of the damaged heart valve requires about 3000 USD. Therefore, Prevention of RF and RHD will not only decrease the morbidity and mortality in the children but also will be ecnomically beneficial.

Ministry of Health and Population has been providing 200 prosthetic heart valves every year to central hospitals like Shahid Gangalal national Heart Center and Bir Hospital for free implantation to poor patients. The list of patients needing valve replacement surgery is quite long. Most of the patients die due to lack of fund for surgery. The most effective and long lasting way to address this problem is to prevent RF and RHD. It is in this context the National RF and RHD prevention \& control program has been launched.

\section{Objectives:}

1) To conduct secondary prophylaxis of RF/RHD by providing injection Benzathine Penicillin free of cost to needy patients through hospitals \& heath centers.
2) To conduct primary prophylaxis of RF/RHD by providing injection Benzathine Penicllin or oral Penicillin to needy children of school going age through health posts and sub-health posts.

3) To establish centers for safe admistration of injection Penicillin.

4) To conduct epidemiological studies on streptococcal infection, RF and RHD.

5) To establish a national strategy for RF/RHD prevention and control in Nepal.

Overall goal:

To reduce the morbidity, disabilities and mortality from RF \& RHD in Nepal.

Components of RF/RHD Prevention \& control program

1) Epidemiological studies.

2) Awareness creation.

3) Training of Health workers.

4) Case detection.

5) Delivery of Medicines for prophylaxis.

6) Community involvement.

7) Evaluation, Monitoring \& Surveillance system.

Phases of implementation

The program is planned to be implemented and expanded phase wise:

Phase-1- Secondary prophylaxis of RF/RHD at central, Regional \& zonal level (Central, Regional * zonal Hospitals)

Phase-2- Secondary prophylaxis of RF/RHD at district level Phase-3- Secondary prophylaxis of RF/RHD at village level (Health posts \& Sub-health posts).

Phase-4- Primary prophylaxis of RF/RHD at village level.

\section{Hospitals involved in this program.}

Initially 22 hospitals were involved in this program. In second year 4 hospitals were added. Now altogether 26 hospitals covering all 14 Zones of $\mathrm{Nepal}$ are involved. Among them 4 are central hospitals, 12 Regional \& zonal Hospitals, 4 district hospital and 6 community hospitals. (Table - 1)

Medicines and materials supplied to the participating hospitals.

The following medicines and materials are supplied to the participating hospitals on regular basis:

1) Inj. Benzathine Penicillin 6 lac \& 12 lac.

2) Tab Erythromycin $250 \mathrm{mg}$.

3) Disposable syringe $3 \mathrm{ml} / 5 \mathrm{ml} / 10 \mathrm{ml}$.

4) Distilled water for injection $5 \mathrm{ml}$ ampoule.

@Nepalese Heart Journal. Nepalese Heart Journal retains copyright and work is simultaneously licensed under Creative Commons Attribution License CC - BY 4.0 that allows others to share the work with an acknowledgement of the work's authorship and initial publication in this journal. 


\section{RF/RHD Registry:}

\section{Hospital Registry}

Each hospital participating in the program has its own registry of RF/RHD patients receiving secondary prophylaxis. These hospitals forward the patients list to cntral (national) registry.

\section{National (Central) Registry}

All the patients registered in this program and receiving penicillin nation wide are enlisted in the National RF/RHD registry list which is maintained at the program office at Nepal Heart Foundation, Babarmahal, kathmandu

\section{Penicillin injection card:}

This card is issued to all the patients receiving secondary prophylaxis Penicillin injection card contains patient information, diagnosis, batch number of injection Benzathine penicillin that patient is receiving, dates of injection given, next injection date and signature of health person delivering injection penicillin.

\section{Epidemiological studies:}

It is planned to conduct national survey on prevalence of RF/RHD in Terai, Mountain and Hilly regions of Nepal to collect national data

\section{Penicillin allergy \& penicillin skin testing}

The incidences of allergic and anaphylactic reactions to Benzathine penicillin injections are reported to be $3.2 \%$ and $0.2 \%$ respectively; fatal reactions are rare $(4,5)$. The risk of a serious reaction is reduced in children under the age of 12 years and the duration of prophylaxis does not appear to increase the risk of an allergic reaction (6-8). The long-term benefits of Benzathine penicillin.

\begin{tabular}{l|l|l|l}
\multicolumn{3}{l}{ Table 1. Participating Hospitals } & \multicolumn{1}{|c}{ Hospital } \\
\hline S.N. & Code No. & \multicolumn{1}{|c}{ District } \\
\hline 1 & C1 & $\begin{array}{l}\text { Shahid gangalal National } \\
\text { Heart Center }\end{array}$ & Kathmandu \\
\hline 2 & C2 & Bir Hospital & kathmandu \\
\hline 3 & C3 & TU Teaching Hospital & kathmandu \\
\hline 4 & C4 & Kanti Children Hospital & Kathmandu \\
\hline 5 & Z1 & Mechi Zonal Hospital & Jhapa \\
\hline 6 & Z2 & Koshi Regional Hospital & Morang \\
\hline 7 & Z3 & $\begin{array}{l}\text { Sagarmatha Zonal } \\
\text { Hospital }\end{array}$ & Saptari \\
\hline 8 & Z4 & Janakpur Zonal Hospital & Dhanusha \\
\hline 9 & Z5 & Lumbini Zonal Hospital & Butwal \\
\hline 10 & Z6 & Bheri Zonal Hospital & Banke \\
\hline 11 & Z7 & Seti Zonal Hospital & kailali \\
\hline
\end{tabular}

\begin{tabular}{|c|c|c|c|}
\hline 12 & $\mathrm{Z} 8$ & $\begin{array}{l}\text { Narayani Sub Regional } \\
\text { Hospital }\end{array}$ & Parsha \\
\hline 13 & Z9 & mahakali Zonal Hospital & Kanchanpur \\
\hline 14 & $\mathrm{Z10}$ & $\begin{array}{l}\text { Western Regional } \\
\text { Hospital }\end{array}$ & Kaski \\
\hline 15 & $\mathrm{Z11}$ & $\begin{array}{l}\text { Mid-Western Regional } \\
\text { Hospital }\end{array}$ & Surkhet \\
\hline 16 & $\mathrm{Z} 12$ & Bharatpur HOspital & Chitwan \\
\hline 17 & D1 & Bhakatapur Hospital & Bhaktapur \\
\hline 18 & D2 & Hetauda Hospital & Makawanpur \\
\hline 19 & D3 & Palpa District Hospital & Palpa \\
\hline 20 & D4 & $\begin{array}{l}\text { Gorkha District } \\
\text { Hospital }\end{array}$ & Gorkha \\
\hline 21 & $\mathrm{CH} 1$ & Patal Hospital & lalitpur \\
\hline 22 & $\mathrm{CH} 2$ & $\begin{array}{l}\text { Sheer Memorial } \\
\text { Hospital }\end{array}$ & Kavre \\
\hline 23 & $\mathrm{CH} 3$ & Dhulikhel Hospital & Kavre \\
\hline 24 & $\mathrm{CH} 4$ & Lalitput Heart Clinic & Lalitpur \\
\hline 25 & $\mathrm{CH} 5$ & $\begin{array}{l}\text { United MIssion } \\
\text { Hospital }\end{array}$ & Palpa \\
\hline 26 & CH6 & Ampiipal Hospital & Gorkha \\
\hline
\end{tabular}

Therapy in preventing RF far outweigh the risk of a serious allergic reaction (6-10)

Penicillin skin testing is recommended to be done in all patients who are to receive injection penicillin. However there are no published guidelines weather it is mandatory or not to perform skin testing before each and every injection in the same patient. Hospitals involved in secondary prophylaxis program in Nepal do not have aunanimous guideline for penicillin skin testing. Some centers perform skin test before each and every injection penicillin whereas some centers limit the test to the first injection penicillin only.

Nepal Heart Foundation is working on this issue and will be publishing a guideline very shortly. RHD patients because of poor cardiac function are more susceptible to vaso-vagal reaction and are at high risk of life threatening arrhythmias (11). All health workers dispensing secondary prophylaxis need proper training in performing penicillin skin test and delivery of intramuscular injection. An emergency care kit should also be made availabele in the penicillin injection room. Attempts have been made to establish a penicillin injection delivery room in all participating hospitals with all necessary emergency medicines \& tools to deal with anaphylactic shock.

Emergency care kits have been distributed to all participating hospitals. Helath workers training at different levels have been performed.

There are no reported deaths from anaphylactic shock during the audit period of 19 months. 29 cases of allergic reactions have been reported so far. 


\begin{tabular}{|c|c|c|c|c|c|c|c|c|c|c|c|}
\hline \multirow{2}{*}{$\mathrm{SN}$} & \multirow{2}{*}{ Hospital } & \multicolumn{3}{|c|}{ Patients } & \multicolumn{2}{|c|}{ Age } & \multicolumn{5}{|c|}{ Diagnosis Pen.Allergy } \\
\hline & & M & $\mathrm{F}$ & Total & $<18 \mathrm{Y}$ & $>18 \mathrm{Y}$ & $\mathrm{RF}$ & RHD & Major & Minor & Deaths \\
\hline 1 & SGNHC & 566 & 797 & 1363 & 261 & 1102 & 6 & 1357 & 1 & 10 & 0 \\
\hline 2 & Bir Hosp. & 88 & 212 & 300 & 49 & 251 & 3 & 297 & 1 & 6 & 0 \\
\hline 3 & TUTH & 27 & 49 & 76 & 12 & 64 & 6 & 70 & 0 & 2 & 0 \\
\hline 4 & Kanti CH & 58 & 35 & 93 & 93 & 0 & 14 & 79 & 0 & 0 & 0 \\
\hline 5 & Patan Hosp. & 98 & 216 & 314 & 266 & 48 & 5 & 309 & 0 & 6 & 0 \\
\hline 6 & Bhaktapur H & 11 & 29 & 40 & 6 & 34 & 5 & 35 & 0 & 1 & 0 \\
\hline 7 & Sheer M.H. & 17 & 35 & 52 & 23 & 29 & 13 & 39 & 0 & 1 & 0 \\
\hline 8 & Dhulikhel H. & 45 & 106 & 151 & 48 & 103 & 10 & 141 & 0 & 1 & 0 \\
\hline \multirow[t]{2}{*}{9} & Lalitpur HC & 49 & 81 & 130 & 23 & 107 & 8 & 122 & 0 & 0 & 0 \\
\hline & Total & 959 & 1560 & 2519 & 781 & 1738 & 70 & 2449 & 2 & 27 & 0 \\
\hline
\end{tabular}

Table 3. Secondary Prophylaxis- Defaulter Cases

\begin{tabular}{|c|c|c|c|c|c|c|c|c|c|}
\hline \multirow{2}{*}{$\mathrm{SN}$} & \multirow{2}{*}{ Hospital } & \multicolumn{3}{|c|}{ Sex } & \multicolumn{2}{|c|}{ Causes of Dropouts } & \multicolumn{3}{|c|}{ Diagnosis Pen.Allergy } \\
\hline & & M & $\mathrm{F}$ & Total & DEATH & PHOBIA & ORAL & COMPLETION & MIGRATION \\
\hline 1 & SGNHC & 76 & 90 & 166 & 0 & 10 & 10 & 17 & 108 \\
\hline 2 & Bir Hosp. & 47 & 57 & 104 & 0 & 9 & 12 & 17 & 48 \\
\hline 3 & TU Teach H. & 16 & 12 & 28 & 0 & 3 & 2 & 2 & 16 \\
\hline 4 & Kanti Ch.H. & 29 & 31 & 60 & 0 & 0 & 0 & 16 & 38 \\
\hline 5 & Patan Hosp. & 20 & 24 & 44 & 0 & 6 & 6 & 5 & 17 \\
\hline 6 & Bhaktapur Hosp. & 1 & 1 & 2 & 0 & 1 & 1 & 0 & 0 \\
\hline 7 & Sheer M. Hosp. & 2 & 3 & 5 & 0 & 1 & 0 & 3 & 1 \\
\hline 8 & Dhulikhel Hosp. & 5 & 8 & 13 & 0 & 2 & 0 & 3 & 6 \\
\hline \multirow[t]{2}{*}{9} & Lalitpur H.Clinic & 11 & 13 & 24 & 0 & 2 & 16 & 3 & 3 \\
\hline & Total & 207 & 239 & 446 & 0 & 34 & 47 & 66 & 237 \\
\hline
\end{tabular}

Patients on secondary prophylaxis from valley group of hospitals

Details of patients receiving secondary penicillin prophylaxis in Valley group of hospitals (Table - 2) during period 20643-15 to 2065-12-30 have been collected. Data collection in other hospitals is in process which will be published soon. In 9 hospitals of valley group there are total 2519 patients receiving 3 weekly injection Benzathine penicillin. Out of them, 1560 $(61.9 \%)$ are female and $959(38.1 \%)$ are males. Diagnosis is RF in $70(2.8 \%)$ and RHD in $2449(97.2 \%), 781(31 \%)$ are below 18 years. Patients receiving 6 lacs are $325(12.9 \%)$ and those receiving 12 lacs are 2194 (87.1\%). A total of 47638 Benzathine penicillin injections were given there were only $29(0.06 \%)$ allergic reactions-2 major and 27 minor. There were no death reported. Out of 2519 patients there were 446 defaulters (those who had missed more than 2 consecutive doses of injection Benzathine penicillin). Out of them 66 had completed the course of prophylaxis, 47 had shifted to other health centers, 34 discontinued prophylaxis due to injection phobia and 62 had other causes. Actual defaulters (dropouts due to injection phobia and other nonspecific causes) wer 96 (3.8\%), (Table-3)
Awareness campaign:

Revision of text books of health education at school level from class 6 to 10 has been completed. Materials on RF and RHD have been now included in the educational curricula. This will help increase awareness in school children and parents. Health education materials on RF and RHD have been transmitted from national TV and radio A 20 minutes duration documentary film on RHD have been produced and transmitted several times from Nepal TV. Large hoarding boards with awareness messages at major public places of several large cities are on display which have played a significant role in awareness creation

\section{CONCLUSION}

RF \& RHD prevention and control program in Nepal has been well accepted by the public \& health professionals. Expansion of the program to the district and village levels is necessary. It should be integrated with the primary health care system. Success of this program will depend upon the political commitment and its continuity. It is too early to make any evaluation about the result of this program. 


\section{REFERENCE}

1. Shrestha U.K., Bhattarai TN, pandey MR. Prevalence of rheumatic fever and rheumatic heart disease in school children in a rural community of the hill region of Nepal. Indian Heart J 1991 jan-Feb ;43(1) ; 39-41

2. K.C man Bahadur, Sharma D, Shrestha MP, Gurung S, Rajbhandari S, Malla R, Rajbhandari R, Limbu YR, Regmi SR, Koirala B.

Prevalence of rheumatic and congenital heart disease in school children on Kathmandu valley in Nepal. Indian Heart J 2003 ;55; 615-618

3. Regmi PR, Pandey MR

Prevention of RF and RHD in school children of Kathmandu city

Indian Heart Journal 1997;49:518-520

4. International rheumatic fever study group. Allergic reactions to long-term banzathine penicillin prophylaxis for rheumatic fever

Lancet 1991, 337, 1308- 1310

5. Markowitz M, Lue HC

Allergic reactions in rheumatic fever patients on longterm benzathine penicillinG; the role of skin testing for penicillin allergy.

Pediatrics, 1996, 97 (s): 981-983

6. Lue HC, Wu MH, Hsein KH, Lin GJ, Hsien RP, Chiou $\mathrm{JF}$

Rheumatic fever recurrences: controlled study of 3- weeks versus 4- weeks benzathine penicillin precention programs.

Journal of pediatrics, 1986, 108: 299-304

7. Dajani AS.

Adherence to physicians instructions as a factor in managing streptococcal phryngitis Pediatrics, 1996, 97 (6 pt 2): 976-980.

8. Wood HF, Feinstein Ar, Taranta A, Epstein JA Simpson R Rheumatic fever in children and adolecents A long term epidemiological study of subsequent prophylaxis, streptococcal infections and clinical sequelae. Comparative effectiveness of there prophylaxis regimens in preventing streptococcal infections and rheumatic recurrences.

Annals of internal medicine, 1964, 60(suppl5): 31-46

9. American Heart Association

Treatment of acute streptococcal pharyngitis and prevention of rheumatic fever : a statement for health professionals

10. WHO model Prescribing information.

Drugs used in the treatment of streptococcal pharyngitis and prevention of rheumatic fever Geneeva, WHO, 1999 (WHO/EDM/PAR/99.1)

11. International Rheumatic fever study group. Allergic reactions to long - term benzathine penicillin prophylaxis of rheumatic fever. Lancet 1991, 337 : 1308-1310. 